\title{
Antropologia e design: um estudo bibliométrico sobre a pesquisa antropológica em conexão com o design dentro de revistas cientificas
}

Anthropology and design: a bibliometric study on anthropology
research applied to design in scientific journals

TEIXEIRA, Samanta Aline

Universidade Estadual Paulista - UNESP I laranjasat@gmail.com

GOMES, Caroline Apolinário

Universidade Estadual Paulista - UNESP I caroline.agomes@gmail.com

LASTRA, Erick Hernán Boschilha

Universidade Federal do Paraná - UFPR I ericklastra@gmail.com

SASAOKA, Silvia

Universidade Estadual Paulista - UNESP I silvia.sasaoka@gmail.com

PASCHOARELLI, Luis Carlos

Universidade Estadual Paulista - UNESP I paschoarelli@faac.unesp.br

\begin{abstract}
Resumo
O presente estudo objetiva ampliar a compreensão sobre antropologia no campo do design através de uma coleta de dados bibliométricos baseados em quatro revistas científicas. Consideram-se as revistas Estudos em Design, Horizontes Antropológicos, Revista Brasileira de Ciências Sociais e uma análise detalhada na revista Design Studies. Investigase a pesquisa científica entre antropologia e design e como essas áreas se conectam para gerar novas formas de conhecimento.

\section{Abstract}

The present study aims to enhance the understanding about anthropology within the design field through the bibliometric data collected from four scientific journals. We consider the journals: Estudos em Design, Horizontes Antropológicos, Revista Brasileira de Ciências Sociais, and a detailed analysis of the Design Studies journal. The scientific research on anthropology and design is investigated, as well as how both fields connect to generate new knowledge.
\end{abstract}

Palavras-chave: Antropologia. Design. Bibliometria. Revista. Pesquisa.

Keywords: Anthropology. Design. Bibliometrics. Journal. Research. 


\section{INTRODUC̣ÃO}

O campo do design está constantemente questionando a realidade inserida a ele enquanto área de conhecimento e ação projetual: qual o papel do designer? O que fazer para melhorar o mundo ao seu redor? Com a incidência cada vez maior de projetos coletivos sociais e ecológicos, a antropologia ganha força de ação, unindo-se ao design em busca de um entendimento mais amplo do ser humano e suas comunidades. Através dos estudos de diversos autores como Anastassakis, Papanek, Ingold, Gunn e Donovan, são evidenciadas ações diretas de designers em união com antropólogos na busca de projetos mais ligados à sociedade, suas culturas, modos de vida e dificuldades do cotidiano. Em uma mistura entre interações sociais, projetos de extensão e pesquisas formais acadêmicas, essa investigação busca através de um estudo bibliométrico entender como o campo da antropologia em design está se manifestando atualmente dentro de algumas revistas científicas. Sob a ótica de uma análise quantitativa, busca-se uma estratégia para poder entender uma das muitas manifestações que a área da antropologia em design alcança.

\subsection{Design e Antropologia no Brasil}

A união metodológica e projetual entre as áreas de conhecimento da antropologia e do design no Brasil têm sido amplamente exploradas pela professora Zoy Anastassakis. Sendo docente da Escola Superior de Desenho Industrial da Universidade Estadual do Rio de Janeiro, Anastassakis tem desenvolvido diversas experiências práticas de interdisciplinaridade entre design e antropologia na mesma universidade desde o ano de 2012. Seu processo investigativo articulou os projetos de extensão, pesquisa e ensino com base nos estudos mais recentes de Tim Ingold, antropólogo britânico (ANASTASSAKIS, 2013, p. 179). Em estudo publicado em 2014, Anastassakis abordou a relevância do tema e da aplicação da prática antropológica no campo do design desde a década de 80, tanto em escritórios profissionais de design como em programas de mestrado versados na área "Design and Anthropology" de dois países: Escócia, na Universidade de Aberdeen, e Austrália, no Departamento de Design da Universidade de Swinbourne. No Brasil, a professora desenvolveu estudos no curso de graduação em design da PUC-Rio de Janeiro, e na especialização em design estratégico da UNISINOS - Rio Grande do Sul (ANASTASSAKIS, 2014, p. 240). Anastassakis busca identificar, através do levantamento de outros pesquisadores, a motivação e a origem da aproximação do design em relação à antropologia. A autora define este conjunto de ações como um movimento que veio transformar a maneira como se pratica o design hoje. Ela analisa os termos históricos e conceituais do "design and anthropology", definindo que esta área atualmente se encontra como um subcampo do design, possuindo características teórico-metodológicas e localizações institucionais específicas. Através dessa 
definição, a antropologia em design está ganhando cada vez mais espaço neste campo profissional-disciplinar (ANASTASSAKIS, 2014, 241). As definições sobre Design e Antropologia podem variar consideravelmente entre diferentes países, culturas e instituições. No caso da Swinburne University of Technology, na Austrália, os pesquisadores indicam que o curso leva à compreensão do que significa o ser humano e a diversidade dos valores humanos, e como são traduzidos esses valores em experiência tangível (ANASTASSAKIS, 2014, p. 242).

[...] O curso de Design e Antropologia tem como foco mudar a visão convencional dos paradigmas modernistas, propondo-se ao engajamento dos alunos com grupos envolvidos incorporando-se aos processos de design os conhecimentos autóctones. Desta forma, são desenvolvidos métodos construídos com base no design social alinhados às intenções e resultados dos processos de design por meio das ferramentas da antropologia. (ANASTASSAKIS, 2014, p. 243).

Já o programa de mestrado em Design e Antropologia da University of Aberdeen, Escócia, iniciou suas atividades acadêmicas em 2012 e em seu website apresenta a definição de "Design Anthropology" como uma interface onde a imaginação de futuros possíveis encontra o estudo comparativo dos saberes humanos e suas diversas formas de viver. Trata-se de um aprofundamento da compreensão a respeito da forma como as pessoas habitam os espaços, constroem e se relacionam com as coisas que usam. Estes dois campos juntos colocam o design em seu mais amplo contexto político e institucional, posicionando-o como corresponsável das questões ambientais, da sustentabilidade e das alternativas em energia. (ANASTASSAKIS, 2014, p. 244). O primeiro designer a questionar a cultura de consumo, os recursos limitados do planeta e a necessidade de mudança do comportamento humano a nível industrial foi Victor Papanek. Nascido em Viena (1927- 1999), Papanek estudou design e arquitetura tardiamente, morou na Inglaterra e emigrou para os Estados Unidos. Foi professor e consultor de diversas universidades na Europa, Ásia e América do Norte (OLIVEIRA; CAMPOS, 2007, p. 2). Papanek ressaltou a importância do contexto social e ambiental, como questões fundamentais para a atuação do designer e afirmava que: "A resposta do design deve ser positiva e unificadora, deve ser a ponte entre as necessidades humanas, a cultura e a ecologia" (PAPANEK, 1995, p. 32). O livro "Design para um mundo real: Ecologia humana e transformação social", escrito entre 1963 e 1970 e publicado nos Estados Unidos em 1971, por Victor Papanek, foi pioneiro ao abordar questões como a preservação de recursos, consumo consciente e ética no discurso do design. Em busca de alternativas ecológicas em design, ele reuniu uma ampla bibliografia de antropologia e difundiu a importância desta nova visão entre os designers durante o século XX (ANASTASSAKIS, 2012, p. 2). 


\subsection{Design e Antropologia no Âmbito Internacional}

Tim Ingold é um antropólogo inglês dos mais influentes atualmente, ocupando a cadeira da antropologia social na Universidade de Aberdeen, na Escócia (UNIVERSITY OF ABERDEEN, 2015). Uma das vertentes de sua pesquisa consiste em aproximar a antropologia do design, ou ainda mais abrangentemente, do campo das artes e projeto: "[...] a arte, a arquitetura e a antropologia têm em comum o ato de observar, descrever e propor. Há, talvez, uma disciplina à espera de ser definida e nomeada, onde estes três campos se encontram" (INGOLD, 2011, p. 11, tradução nossa). Ingold desenvolve análises teóricas e práticas que buscam abrir um diálogo para os novos possíveis rumos que a antropologia pode compor com outras áreas, sobretudo em busca de que a área se atualize e interfira na sociedade de modo mais ativo. $\mathrm{Na}$ emergência dessas novas metodologias antropológicas que atuam dentro da interdisciplinaridade, Ingold abriu portas para outros pesquisadores buscarem as respostas de tal questionamento às suas próprias maneiras, como Wendy Gunn e Jared Donovan, na University of Southern Denmark - Dinamarca. Assim como Gunn e Donovan buscam a prática da antropologia e design no grupo laboratorial SPIRE - Sondenborg Participatory Research Centre (GUNN; DONOVAN, 2012), Anastassakis busca essa mesma prática dentro do cenário brasileiro no LADA - Laboratório de Design e Antropologia (ANASTASSAKIS, 2013). Anastassakis confirma um novo tipo de antropologia mais ativa, indicado inicialmente por Ingold:

Uma antropologia entendida como modo inquisitivo de estar no mundo, em que o compromisso com a observação e a descrição esteja conjugado a um engajamento propositivo no sentido de uma transformação desse mesmo mundo, algo mais aproximado da liberdade criativa que é convencionalmente delegada às disciplinas como a arte, a arquitetura e o design. (ANASTASSAKIS, 2013, p. 182).

Gunn e Donovan também abrem novos caminhos paradigmáticos diante desse novo ramo emergente, especialmente ao adotarem em suas metodologias laboratoriais o trabalho em equipe com profissionais em distintas áreas do conhecimento:

Antropologia em Design é um campo emergente e consiste em múltiplas práticas. Em termos de formação universitária, o contexto institucional promove abordagens diferentes para ensinar Antropologia em Design. No SPIRE nós trabalhamos juntos como parte de uma equipe de pesquisa colaborativa, envolvendo pesquisadores com formação em antropologia, design, engenharia, linguagem e comunicação, negócios e estudos de inovação. (GUNN; DONOVAN, 2012, p. 1, tradução nossa). 
Diante de tal cenário em que surgem diversos laboratórios práticos e teóricos, incorporando maior importância institucional à antropologia em design, cabe aqui um estudo mais apurado de como essa aproximação de áreas se dá no âmbito acadêmico.

\section{DESENVOLVIMENTO}

Sabe-se que a antropologia em design já foi analisada dentro de um estudo bibliométrico nos anais do Congresso P\&D (BARCELLOS et al., 2015). Para complementar essas informações, buscou-se aqui entender e explanar o cenário da pesquisa de antropologia em design em quatro revistas científicas consideradas relevantes nesse ramo: as nacionais Estudos em Design, Horizontes Antropológicos, Revista Brasileira de Ciências Sociais; e a internacional Design Studies. Tratando-se de um campo vasto e complexo, foram precisos determinados critérios para especificar dentro das revistas os assuntos de interesse deste estudo. Uma das formas de busca para tal análise foi a adoção de palavras-chaves de acordo com o trabalho do grupo laboratorial SPIRE, desenvolvido por Gunn e Donovan, que também serviu de referência para as instrumentações da pesquisadora Anastassakis. A seguir, segue um esquema de gráfico resumindo as áreas de interesse do grupo SPIRE:

Figura 1 - Figura do grupo laboratorial SPIRE, desenvolvido pelos estudiosos Gunn e Donovan.

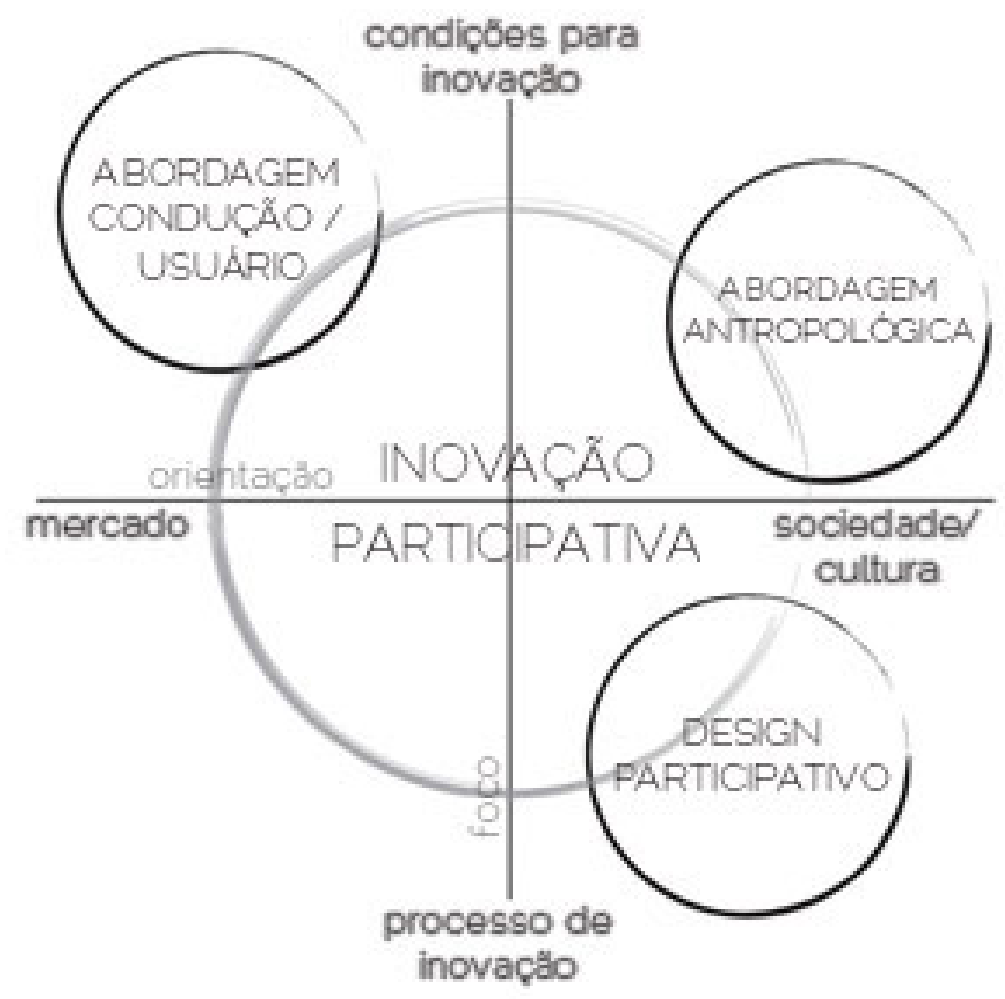

Fonte: Adaptado de Spire (2015). 
Os campos circulados indicam as áreas de interesse de estudo do grupo e suas possíveis convergências, na tentativa de elucidar uma investigação interdisciplinar da Antropologia em Design. Dentro da contextualização do novo conceito de antropologia em design, Gunn e Donovan deixam claro que as ações de participação, inovação e colaboração possuem fundamental papel dentro de tal construção institucional:

Na base de nossas investigações, "inovação participativa" tem sido uma preocupação dentro da busca de alternativas em envolver os povos dentro da concepção colaborativa e atividades de inovação participativas que, de outra forma, seriam excluídas dos processos e práticas de design e inovação. (BURR; MATHEWS, 2008 apud GUNN; DONOVAN, 2012, p. 4, tradução nossa).

Os autores pontuam um dos fatores positivos da adoção antropológica em projetos criativos: a colaboração e inovação participativa não costumavam ser contemplados em práticas do design. A antropologia serviu de ponte paradigmática para alcançar objetivos criativos mais conectados com a comunidade, a responsabilidade social e a sustentabilidade. Uma outra forma adotada para a busca das palavras-chaves foi através de Ingold, cuja pesquisa indicia nas artes manuais e na cultura de materiais sua importância dentro da antropologia como um todo:

\begin{abstract}
Passando desde suas sensibilidades subjacentes às suas práticas de trabalho, a antropologia é talvez mais parecida com artesanato do que arte. Pois é característica do artesanato o conhecimento do praticante das coisas, e o que ele faz para essas coisas é baseado em relações intensas, respeitosas e íntimas com as ferramentas e materiais do seu comércio. (INGOLD, 2011, p. 229, tradução nossa).
\end{abstract}

Tendo essas premissas como base, foi possível traçar uma estratégia de busca de termos que se conectassem com o tema antropologia em design de maneira mais objetiva.

\title{
2.1 A Pesquisa Etnográfica no Campo do Design
}

A etnografia é um método da antropologia envolvendo estratégias de contato com o objeto de estudo e inserção no campo que resultam em pesquisa escrita. Na área do design, o método etnográfico é usado em grande parte por designers como processo de busca de informações a respeito do usuário de um produto ou serviço. O termo etnografia quando aplicado ao design tem seu significado mais restrito aos olhos dos antropólogos, segundo Wasson (2000, p. 382). Com uma redução expressiva de contextualização teórica, a pesquisa 
etnográfica no campo do design é aplicada de forma direta, com abordagem mais rápida do que outras metodologias acadêmicas em antropologia. $\mathrm{A}$ análise de dados coletados e o material etnográfico são configurados pelas necessidades particulares dos designers industriais. Ainda de acordo com Wasson, o método e abordagem podem variar até mesmo de empresa para empresa. Um caso pioneiro de contratação de antropólogos por uma grande indústria ocorreu no ano de 1980 com a Xerox Palo Alto Research Center (PARC). Lucy Suchman e sua equipe adotaram o método etnográfico em pesquisa de design de softwares nos Estados Unidos (BLOMBERG et al., 1993 apud WASSON, 2000).

\section{MATERIAL E MÉTODOS}

Inicialmente foi realizado um estudo preliminar de antropologia em revistas internacionais e nacionais levando em consideração a quantidade de resultados. Optou-se pela busca de publicações utilizando outros termos relacionados à antropologia para obtenção de resultados de buscas mais precisos com o tema antropologia em design. Diante desse estudo, os termos adotados na busca bibliométrica, além dos próprios termos "antropologia", foram: design colaborativo; inovação participativa; design participativo; cultura material; artesanato e comunidade - e suas respectivas traduções em inglês para as buscas dentro da revista internacional Design Studies (SCIENCE DIRECT, 2015). Por fim, o termo "etnografia" foi considerado nas buscas pela relevância que possui dentro do campo do Design. O método de busca para a revista Design Studies foi através da base de dados online Science Direct que possui todo o acervo da revista de 1979 até 2015. No caso da revista Estudos em Design, a pesquisa foi realizada diretamente no site da mesma, que disponibiliza seus volumes dos anos de 2007 até 2015 (ESTUDOS EM DESIGN, 2015). Num esforço adicional para encontrar publicações relacionando Antropologia e Design, foram realizadas buscas com o termo "Design" dentro de duas revistas brasileiras relacionadas à Antropologia: Horizontes Antropológicos e Revista Brasileira de Ciências Sociais. O intuito foi observar a inserção do Design no meio científico da Antropologia e não somente o inverso. O Portal Scielo foi utilizado na busca (SCIELO, 2015) para ambas as revistas brasileiras, que disponibiliza as edições da Horizontes Antropológicos de 1999 à 2015, e de 1997 à 2015 para a Revista Brasileira de Ciências Sociais.

\section{RESULTADOS E DISCUSSÕES}

\subsection{Panorama Internacional}

Em âmbito internacional, a revista científica escolhida foi a Design Studies, uma revista focada no desenvolvimento, compreensão e discussão dos aspectos fundamentais da atividade de design. Sua primeira edição é de 1979 
e, para essa pesquisa, estamos considerando um total de 1845 publicações, contemplando até o ano de 2015. O primeiro aspecto analisado diz respeito a quantidade de publicações que possuem conexão com as palavras-chaves "anthropology" e "ethnography". Neste caso, nota-se de início que os números de publicações envolvendo essas áreas são baixos em relação ao total de publicações da revista. Foram encontradas 42 publicações com o termo "anthropology" (2,2\% do total) e 37 com o termo "ethnography" (2\% do total de publicações). Pelo Gráfico 1 é possível observar o número de publicações por ano com as palavras-chaves "anthropology" e "ethnography" desde a primeira edição da Design Studies.

Gráfico 1- Total de publicações por ano e publicações com o termo Etnografia e Antropologia.

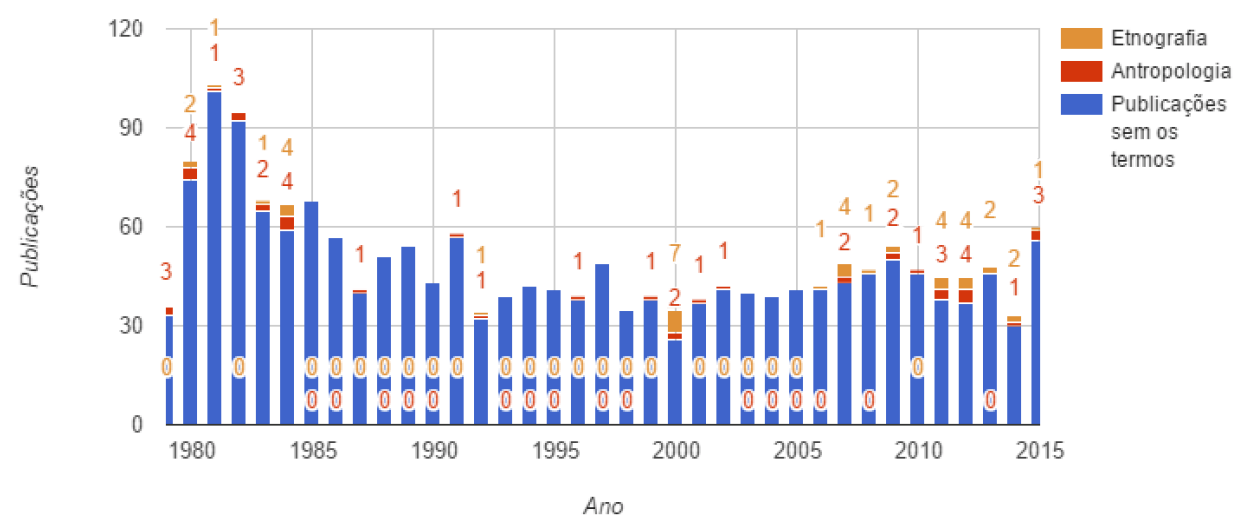

Fonte: Elaborado pelos autores.

Além da pequena expressão de artigos que envolvem antropologia e etnografia em seu conteúdo, nota-se que as publicações com a palavra-chave "anthropology" não ultrapassa a faixa de 4 publicações em 2012; enquanto que as publicações com a palavra-chave "ethnography" atingem o pico de 7 publicações no ano 2000. Por outro lado, as publicações se mantêm contínuas desde a primeira edição. $O$ Gráfico 2 exibe o comparativo entre os dois termos ao longo dos anos. Através das linhas de tendência é possível observar que o termo "antropologia" vem diminuindo ao passo que "etnografia" vem aumentando. Tal informação sugere que o termo antropologia possa estar sendo substituído por etnografia ao longo dos anos, ou ainda por outros termos correlatos conforme explorados ao longo do presente trabalho. 
Gráfico 2 - Linhas de tendência das palavras "anthropology" e "ethnography", de 1979 a 2015.

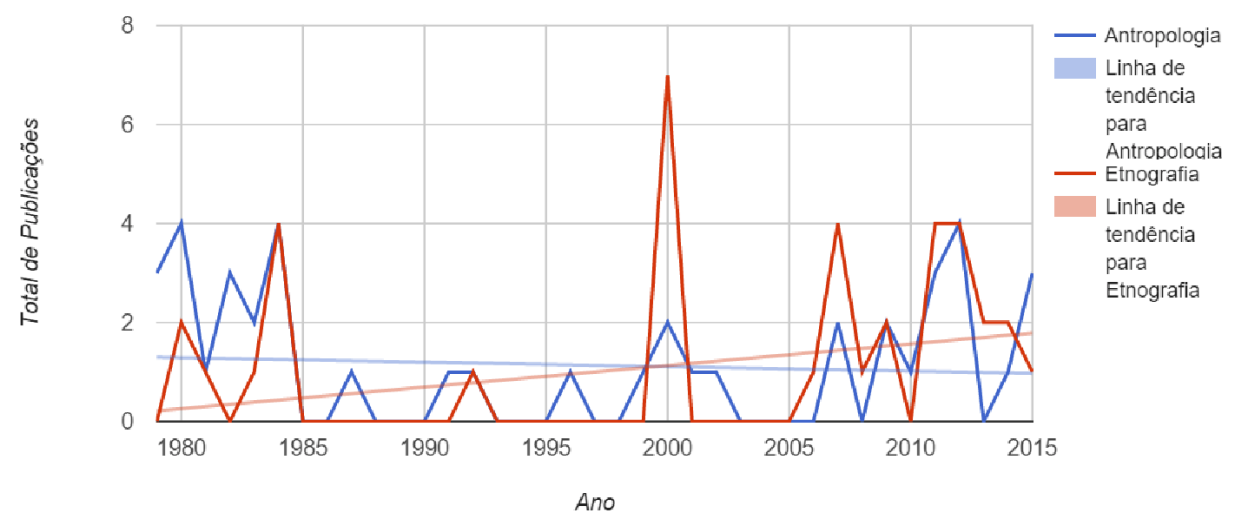

Fonte: Elaborado pelos autores.

Após a realização da etapa acima, foram analisados as quantidades e locais de publicações dos artigos encontrados com a palavra "anthropology". Para realizar uma análise mais apurada, optou-se por excluir os editoriais, conferências e outras formas de publicações que não fossem artigos completos. Dessa forma, foram analisados nessa etapa 29 artigos das 42 publicações encontradas com a palavra "anthropology". Para os artigos que apresentaram mais de um autor, optou-se por adicioná-lo em todos os países envolvidos.

Figura 2- Publicações com a palavra "anthropology" separadas por país.

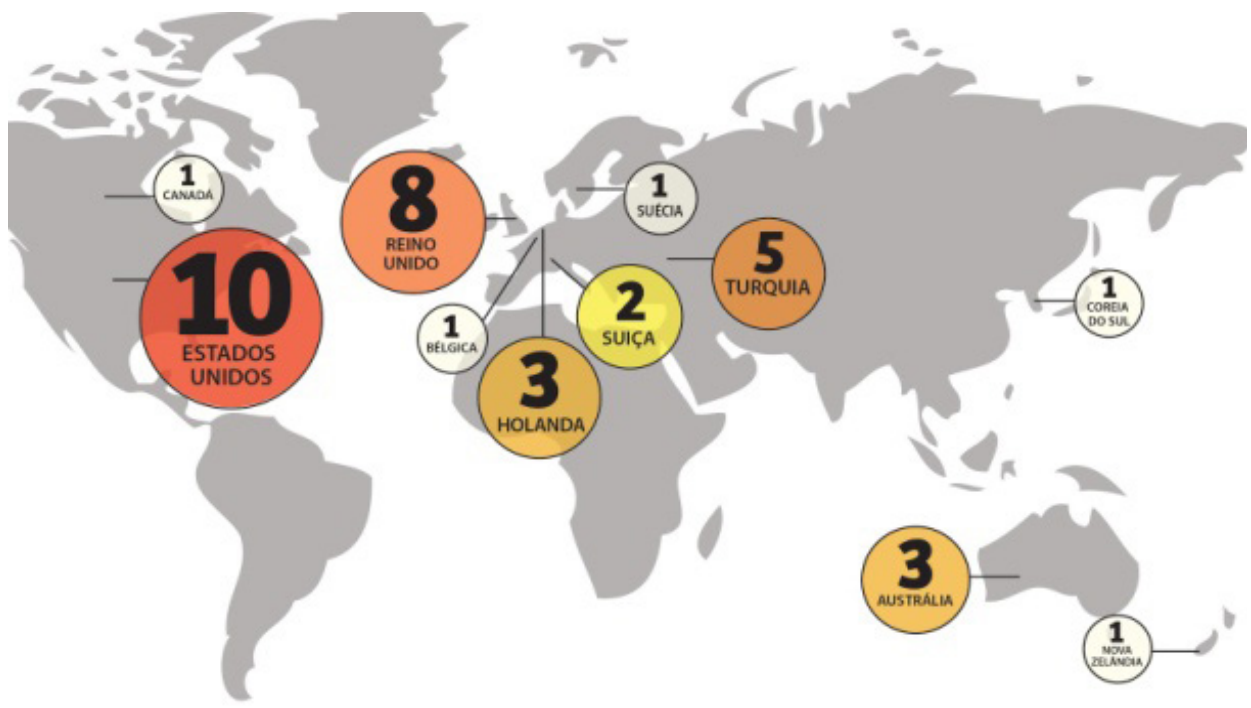

Fonte: Elaborado pelos autores.

Na figura 2 é possível observar a concentração maciça de artigos no hemisfério Norte (com exceção da Austrália e Nova Zelândia). Os países com publicações mais expressivas são os Estados Unidos, com um total de 10 autores, e em seguida, o Reino Unido - mais especificamente a Inglaterra - 
com 8 autores. Em terceiro lugar, destaca-se a Turquia com cinco autores, e os demais países variam de um a três autores. Abaixo, segue um quadro com os países citados na figura 2 e seus respectivos anos de publicação.

Quadro 1 - Quadro com a quantidade de publicações por ano com a palavra "anthropology".

\begin{tabular}{|c|c|c|c|c|c|c|c|c|c|c|c|c|c|c|c|c|c|c|c|c|c|c|c|c|}
\hline & ô & & $\bar{\sigma}$ & |ֶ. & $\mid \begin{array}{l}\mathbf{g} \\
\stackrel{\alpha}{2}\end{array}$ & & 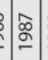 & 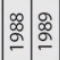 & ఏ잉 & $\sigma \delta$ & ळু & $=\left[\begin{array}{l}2 \\
\hdashline\end{array}\right.$ & ๕ু & ר̊ & & ర్లె & స్రి & ర్లిర్లిర్లి & ¿্ণ & ठ্సి & : & & 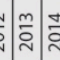 & ง \\
\hline Estados Unidos & & & & 1 & 2 & & & & & \begin{tabular}{l|l|l}
1 & 1
\end{tabular} & & & 1 & & & 1 & 1 & & & & & & & 2 \\
\hline Reino Unido & 2 & 1 & 2 & & & & 1 & & & & & & & 1 & 1 & & & & & & 1 & & & \\
\hline Turquia & & 2 & 2 & & & & & & & & & & & & & & & & 1 & & & & & 2 \\
\hline Holanda & & & & & & & & & & & & & & & & & & & & & & 3 & & \\
\hline Austrália & & & & & & & & & & & & & & & 1 & & 1 & & & & & & & \\
\hline Suiça & & & 1 & 1 & & & & & & & & & & & & & & & & & & & & \\
\hline Bélgica & & & & & & & & & & & & & & & & & & & & & & & 1 & \\
\hline Coreia do Sul & & & & & & & & & & & & & & & & & & & & & & 1 & & \\
\hline Canadá & & & & & & & & & & & & & & & & & & & & & & 1 & & \\
\hline Suécia & & & & & & & & & & & & & & & & & 1 & & & & & & & \\
\hline Nova Zelândia & & & & & 1 & & & & & & & & & & & & & & & & & & & \\
\hline
\end{tabular}

Fonte: Elaborado pelos autores.

Ao analisar o quadro acima, nota-se que os Estados Unidos, além de ser o país com maior número de publicações com a palavra-chave "anthropology", possui também uma produção científica contínua desde 1984, sendo também o país com maior número de produções do ano 2000 até 2015. Em contraponto, o Reino Unido - ocupando o segundo lugar em número de publicações - não possui um padrão frequente de publicações, aparecendo um artigo ou outro em anos muito distantes, como em 1999 e 2010 . Apesar de países como a Turquia e Holanda possuírem uma produção menor em questão de números absolutos, suas publicações são mais recentes. Observa-se ainda que dos 11 países com publicações, apenas a Suíça e a Nova Zelândia não possuem publicações nos últimos 10 anos. A última análise feita na revista internacional Design Studies tem a intenção de verificar os conteúdos abordados nos artigos com a palavrachave "anthropology". Para uma coleta de dados mais efetiva, optou-se por excluir os editoriais, conferências e outras formas de publicações que não sejam artigos completos (assim como na analises feita sobre os locais e ano de publicação). Ao todo foram analisados 29 artigos completos. Com base na investigação individual de cada um dos títulos, resumos e palavras-chave, tornou-se possível dividir os artigos em categorias. As categorias encontradas versam sobre as diversas maneiras em que a antropologia se insere dentro do contexto do design, bem como contribuem para a melhor compreensão de suas relações com outras áreas de conhecimento. Na figura 3 é possível observar a divisão dos artigos pelas categorias. São elas: estudos em design, metodologia, arquitetura, processos cognitivos, etnografia, comportamento humano, sustentabilidade, engenharia, objetos e semiótica. 
Figura 3 - Conteúdo dos artigos encontrados com o termo "anthropology" na Design Studies.

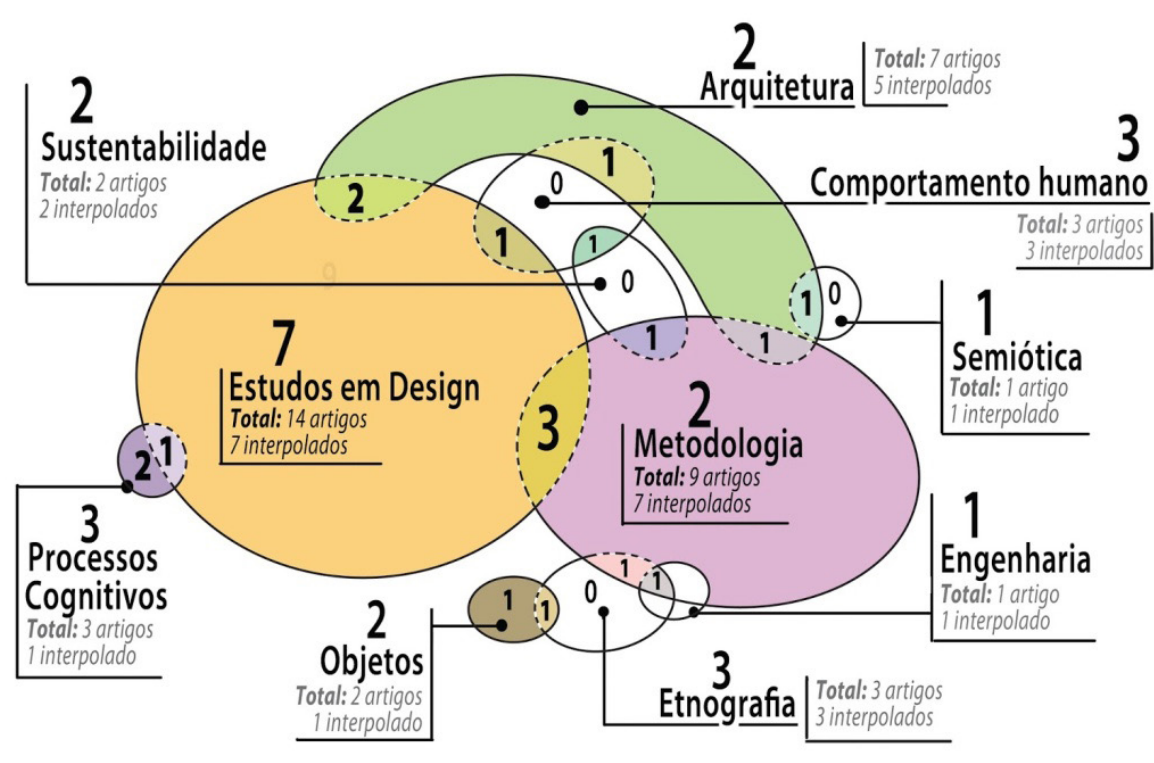

Fonte: Elaborado pelos autores.

$\mathrm{Na}$ figura acima, os trabalhos analisados foram separados em 10 categorias, sendo possível perceber um grande número de interpolações entre as mesmas. Em geral, utilizou-se o esquema de interpolações em círculos como vistos na figura acima para poder representar melhor o caráter do que é a área da Antropologia em Design: um campo de pesquisa extremamente diversificado e híbrido, que não pode ser categorizado em apenas uma área de pesquisa, mas que conversa com diversas outras formas de obtenção do conhecimento e processos projetuais.

Nota-se que a categoria com maior concentração de artigos é a de estudos em design, com o total de 14 publicações. Mais especificamente dentro dessa categoria encontram-se os seguintes subtemas: o estudo de design e sua aplicação prática; a história do design em conexão com as artes; a transdisciplinaridade e a interdisciplinaridade como práticas do design; a relação entre design e arquitetura; o desenvolvimento do design com foco social; entre outros. Vale ressaltar que vários dos artigos analisados foram enquadrados em mais de uma categoria por possuírem diálogos importantes com as mesmas. A segunda maior concentração de artigos encontra-se na área Metodologia com 9 publicações, onde é possível verificar um amplo diálogo com outras categorias. Dentro de metodologia, os subtemas explorados versam sobre o encontro da antropologia com o design thinking; as novas formas de aproximação do homem-artefato; propostas metodológicas de design para a sustentabilidade; metamétodos para problemas na teoria do design; design participativo com a união da arquitetura; metodologias projetuais envolvendo engenharia; métodos para elaboração de projetos (como etnografia, por exemplo); entre outros. A categoria Arquitetura, com 7 publicações, é a terceira mais expressiva em número de artigos. Nesta categoria, assim como em Metodologia, observa-se 
que a maior parte dos trabalhos encontra-se conectados com outras áreas. Seus subtemas versam sobre o comportamento humano e a interação com ambientes projetados; análises críticas sobre os diálogos da arquitetura com o design; design participativo em comunhão com a arquitetura; objetos arquitetônicos e semiótica; entre outros. A categoria Etnografia, com 3 publicações, possui trabalhos sobre métodos etnográficos para o desenvolvimento de um sistema de gestão de conhecimento; estudos etnográficos para desenvolvimento de produtos em diálogo com a engenharia; metodologias e etnografia. Como já dito anteriormente, a etnografia é um método, e neste caso, poderia ser encaixada na categoria Metodologia. Porém, por se tratar de um método expressivo para o diálogo entre design e antropologia, tornando-se uma área de atuação praticamente independente, optou-se pela criação da categoria etnografia separadamente. Na sequência, também com 3 publicações, encontra-se a categoria Processos Cognitivos, com trabalhos sobre percepção; processos verbais e não verbais; e a importância da visão/imagem. Em seguida, a categoria Comportamento Humano, com 3 publicações, discorre sobre a interação pessoa/ambiente (já mencionado na categoria Estudos em Design); a mudança de comportamento através de produtos sustentáveis; e abordagens da micro sociologia e psicologia social voltadas para compreensão da comunicação. A categoria Sustentabilidade possui apenas 2 artigos e ambos encontram-se conectados com outras áreas já mencionadas. A categoria Objetos, também com 2 publicações, abrange estudos etnográficos para o desenvolvimento de produtos (já mencionado na categoria Etnografia) e sobre os conceitos de função, objeto físico e não físico. Por fim, as categorias Semiótica e Engenharia, com apenas 1 publicação discorrem sobre temas já citados nas categorias Metodologia e Arquitetura.

\subsection{Panorama Nacional}

Em âmbito nacional, foi considerada a revista Estudos em Design, que possui um total de 142 artigos disponíveis em seu portal próprio, com edições que abrangem os anos de 2007 até 2015. Não se encontrou resultados através do termo "antropologia", mas sim através dos outros termos correlatos. A tabela 2 faz uma comparação entre os resultados da revista Design Studies e a da Estudos em Design, sendo que a figura 3 exibe o comparativo de ocorrências dos termos em porcentagem com o total de publicações disponíveis. A tabela exibe o total de publicações por termos nas duas revistas com o percentual de ocorrências dos termos em relação ao total de publicações de cada uma das revistas. De todos os artigos registrados, 17 publicações da Estudos em Design (aproximadamente 12\%) possui relação com a antropologia. Por fim, percebe-se que de todos os termos de busca os que mais se encontraram resultados dentro da Estudos em Design foram as palavras cultura material e artesanato, sendo esses termos os que mais provavelmente tem maior apropriação e identificação cultural no Brasil. Já a Design Studies possui um maior apropriação da expressão collaborative design, um termo de estudo antropológico mais recente. 
Quadro 2 - Publicações por termos nas revistas Design Studies e Estudos em Design.

\begin{tabular}{|c|c|c|c|c|c|}
\hline & rmos & Design $\mathrm{S}$ & Idies & Estudose & Design \\
\hline Total de publ & icaões na revista & 1845 & $100 \%$ & 142 & $100 \%$ \\
\hline Português & Inglês & $\begin{array}{c}n \underline{0} \\
\text { publicações }\end{array}$ & $\%$ & $\begin{array}{c}n \underline{0} \\
\text { publicações }\end{array}$ & $\%$ \\
\hline antropologia & anthropology & 42 & $2,3 \%$ & 0 & $0 \%$ \\
\hline artesanato & craft & 255 & $13,8 \%$ & 5 & $3,5 \%$ \\
\hline comunidade & community & 473 & $25,7 \%$ & 8 & $5,6 \%$ \\
\hline cultura material & culture materials & 300 & $16,3 \%$ & 1 & $0,7 \%$ \\
\hline design colaborativo & collaborative design & 244 & $13,2 \%$ & 2 & $1,4 \%$ \\
\hline design participativo & participatory design & 118 & $6,4 \%$ & 1 & $0,7 \%$ \\
\hline etnografia & ethnography & 37 & $2,0 \%$ & 0 & $0 \%$ \\
\hline inovação participativa & participatory innovation & 40 & $2,2 \%$ & 0 & $0 \%$ \\
\hline
\end{tabular}

Fonte: Elaborado pelos autores.

Gráfico 3 - Comparativo de termos entre as revistas Design Studies e Estudos em Design

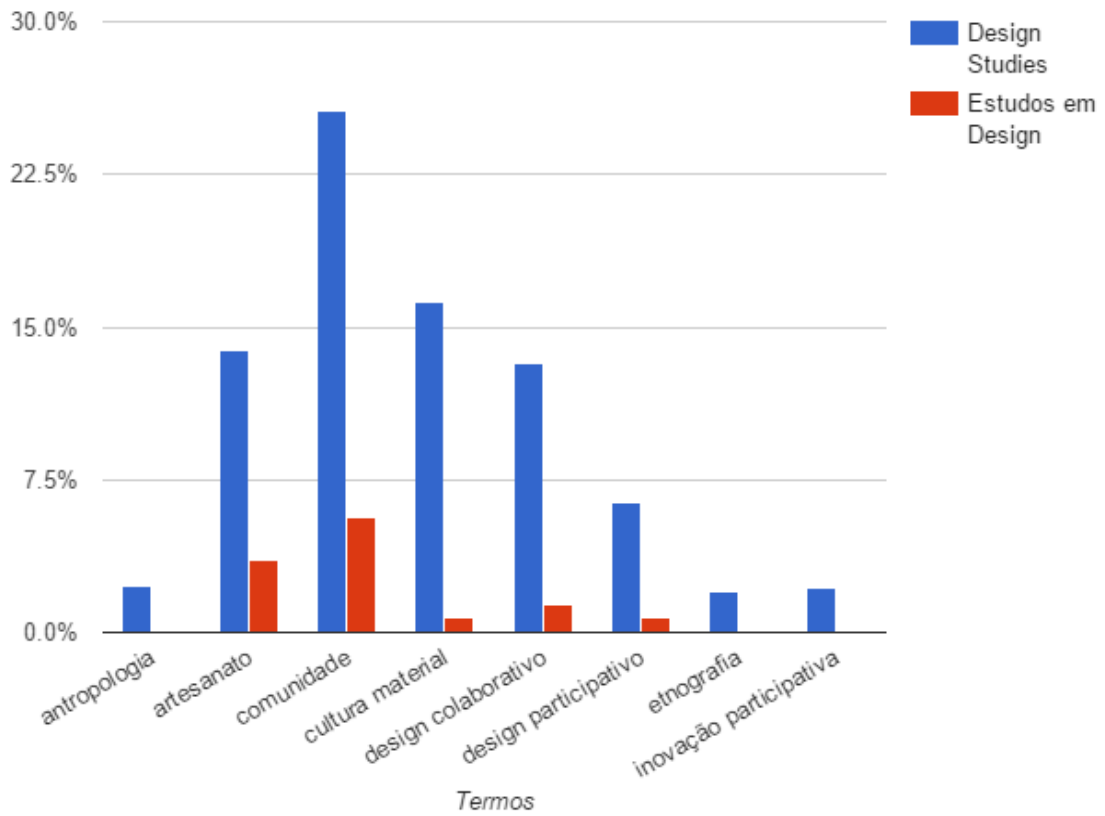

Fonte: Elaborado pelos autores.

Por fim, consideraram-se duas revistas que são da área da Antropologia para fazer o caminho inverso de busca com o termo design. Na revista Horizontes Antropológicos obteve-se o resultado de 4 artigos com o termo Design do total de 217 publicações registradas. Na Revista Brasileira de Ciências Sociais encontrou-se 6 publicações do total de 280. Esses resultados demonstram a escassez da presença do design inserido na antropologia brasileira, pelo menos no que se refere a esse termo propriamente dito. Sabe-se que o significado da palavra design pode variar bastante de acordo com a área de pesquisa, trata-se 
de uma área abrangente e particular para cada situação de estudo. Caberá em algum próximo estudo entender também a variação e ocorrência da área do design inserido em outros campos do conhecimento, especialmente em âmbito nacional.

\section{CONSIDERAC̄ÕES FINAIS}

$\mathrm{Na}$ primeira parte dessa pesquisa, que envolve o levantamento bibliográfico, chega-se à constatação de que o campo do design adquiriu contribuições consideravelmente positivas ao envolver os conhecimentos da antropologia tanto em seus métodos científicos quanto em suas ações projetuais. Através da leitura dos diversos relatos registrados em artigos, congressos, encontros e sites, percebe-se que os pesquisadores, os designers e os antropólogos, ao unirem forças, ampliaram suas visões de mundo diante do meio ambiente, da responsabilidade social e das metodologias projetuais transdisciplinares. Dinâmicas em laboratórios de pesquisa com membros de empresas que utilizaram a prática etnográfica junto a usuários permitiu que se reconhecessem as reais necessidades relacionadas ao uso de serviços ou produtos. Por sua vez, com tal prática, os produtos e/ou serviços apresentaram resultados reveladores e, consequentemente, inovadores. Na segunda parte dessa pesquisa, a etapa bibliométrica, houve uma dificuldade em se encontrar a metodologia e o local de enfoque mais apropriado. Isso porque a Antropologia em Design se trata de uma área recente, que ainda está se construindo, mas que já possui um caráter complexo e diversificado se fazendo presente em diversas outras áreas do conhecimento, da pesquisa e extensão universitáriocomunitária. De modo geral, encontrou-se um número de artigos não tão expressivo se comparado a outras áreas de mais familiaridade para os designers como inovação, ensino e tecnologia. Contudo, analisando os artigos que envolvem a antropologia em design, caso a caso, percebe-se que os temas são específicos e relevantes devido aos seus teores voltados para as comunidades locais, unindo-se com outras áreas importantes como engenharia, semiótica, arquitetura e sustentabilidade. A Antropologia em Design abre as portas para diferentes abordagens, trazendo à tona inovação em metodologia e projeto social. Com relação aos dados bibliométricos: no levantamento das publicações internacionais na revista Design Studies, o tema "Design e Antropologia" (com 1845 artigos encontrados), aparece em maior proporção do que na busca pelos termos "anthropology" e "ethnography" isolados (42 e 37 artigos encontrados respectivamente), o que pode indicar que a área Antropologia em Design está se consolidando aos poucos e ganhando força de expressão e investigação científica. Percebe-se que a concentração de artigos é mais expressiva no hemisfério Norte, sendo que o maior número de publicações se encontra nos Estados Unidos, Reino Unido e Turquia. Outros países como Holanda, Bélgica, Coreia do Sul e Canadá, apesar de apresentarem um número menor de publicações, possuem uma produção científica mais recente, a partir de 2010. 
Dos artigos analisados, percebe-se que os mesmos se enquadram em mais de uma categoria de busca por possuírem diálogos transdisciplinares, as conexões envolvem os seguintes temas interpolados: estudos em design, metodologia, arquitetura, processos cognitivos, etnografia, comportamento humano, sustentabilidade, engenharia, objetos e semiótica. De acordo com as revistas analisadas em âmbito nacional, percebe-se que a pesquisa da Antropologia em Design ainda é tímida, pelo menos em termos de números consistentes para um estudo bibliométrico. Por isso, tornou-se necessário adotar dois caminhos: a busca da antropologia em revistas de design e a busca do design em revistas de antropologia. Dos 142 artigos registrados na revista brasileira Estudos em Design, 17 possuíam algum vínculo com a Antropologia. Das 217 publicações da revista de antropologia brasileira Horizontes Antropológicos, apenas 4 artigos envolviam o termo design. Já na Revista Brasileira de Ciências Sociais dos 280 artigos considerados, 6 publicações possuíam vínculo com o design. Para uma maior sinergia entre as áreas seria necessário também que o Design fosse mais presente entre a comunidade científica de áreas da Ciência Social, fomentando assim uma maior colaboração e multiplicação de esforços entre as áreas. Esse estudo contribuiu para estimular a discussão sobre o tema e levantou perguntas que ainda podem ser investigadas. Entre elas destacam-se as linhas de tendência na diminuição do termo "antropologia" e no aumento do termo "etnografia". Uma das sugestões interpretadas é de que os métodos etnográficos encontram-se intimamente atrelados a pesquisa em Design devido ao seu caráter de ação direta mais conectada à comunidade. Espera-se que essa investigação tenha contribuído para o crescimento e consolidação da área de Antropologia em Design como um todo. 


\section{REFERÊNCIAS}

ANASTASSAKIS, Zoy. A antropologia do design: observações sobre as apropriações da prática antropológica pelo design hoje. In: REUNIÃO BRASILEIRA DE ANTROPOLOGIA, 28., 2012, São Paulo. Anais... São Paulo: Universidade Estadual do Rio de Janeiro, 2012. Disponível em: <https://www. academia.edu/4108765/A_antropologia_do_design_observações_sobre_as_ apropriações_da_prática_antropológica_pelo_design_hoje>. Acesso em: 16 dez. 2015.

ANASTASSAKIS, Zoy. Design and anthropology: an interdisciplinary proposition. In: INTERNATIONAL FORUM OF DESIGN AS A PROCESS, 4., 2014, Barbacena. Proceedings... Barbacena: Universidade Estadual de Minas Gerais, 2014. Disponível em: <http://uerj.academia.edu/ZoyAnastassakis>. Acesso em: 16 dez. 2015.

ANASTASSAKIS, Zoy. Laboratório de design e antropologia: preâmbulos teóricos e práticos. Arcos Design, Rio de Janeiro, v. 1, n. 7, p. 178-195, jul. 2013. Disponível em: <http://www.epublicacoes.uerj.br/index.php/arcosdesign>. Acesso em: 16 dez. 2015.

BARCELLOS, Ekaterina E. I.; MERCALDI, Marlon; PASCHOARELLI, Luis C.; BOTURA JUNIOR, Galdenoro. De Redig ao P\&D: a trajetória da abordagem da antropologia no design. In: INTERNATIONAL CONFERENCE ON DESIGN, ENGINEERING, MANAGEMENT FOR INNOVATION, 4., 2015, Florianópolis. Anais... Florianópolis: Universidade Estadual de Santa Catarina, 2015. Disponível em: <http://janainaramos.com.br/idemi2015/ anais/02/140606. pdf>. Acesso em: 13 dez. 2015.

ESTUDOS EM DESIGN. Rio de Janeiro: PUC, 2015. Disponível em: <http:// estudosemdesign.emnuvens.com.br/design/search>. Acesso em: 13 dez. 2015.

GUNN, Wendy; DONOVAN, Jared. Design and anthropology. Surrey and Burlington: Ashgate, 2012.

INGOLD, Tim. Being alive: essays on movement, knowledge and description. Nova lorque: Taylor \& Francis e-Library, 2011. 
OLIVEIRA, Fernando Alvarus; CAMPOS, Jorge Lucio. O design responsável de Victor Papanek. Agitrop, Campinas, v. 46, n. 4, p. 1-2, 2007. Disponível em: $<$ http://www.agitprop.com.br/index.cfm?pag=ensaios_det\&id=103\&titulo>. Acesso em: 15 dez. 2015.

PAPANEK, Victor. Arquitectura e design: ecologia e ética. Lisboa: Edições 70, 1995.

SCIELO. Scientific Electronic Library Online. Disponível em: <http://www. scielo.br/scielo.php?lng=en>. Acesso em: 13 dez. 2015.

SCIENCE DIRECT. Design studies. Disponível em: <http://www.sciencedirect. com/science/journal/0142694X>. Acesso em: 13 dez. 2015.

SPIRE in University of Southern Denmark. Disponível em: <http://www.sdu.dk/ en/Om_SDU/Institutter_centre/C_SPIRE>. Acesso em: 13 dez. 2015.

UNIVERSITY OF ABERDEEN. Professor Timothy Ingold. Disponível em: <http://www.abdn.ac.uk/socsci/people/profiles/tim.ingold>. Acesso em: 13 dez. 2015.

WASSON, Christina. Ethynography in the field of design. Human Organization, Washington, v. 59, n. 4, p. 377-388, jan. 2000. Disponível em: <https:// designstudiesdiscourses.files.wordpress.com/2013/09/wasson-ethnographyin-field-of-design.pdf>. Acesso em: 17 dez. 2015. 


\section{TEIXEIRA, Samanta Aline; et al}

Submissão: 07-2016

Aceite: 07-2017 